\title{
Free recall of trigrams in the presence of distractors: A replication
}

\section{CHARLES N. COFERI and PETER W. DORFMAN, University of Maryland, College Park, Md. 20742}

$A$ replication of an experiment in which the influence of the presence of distractors on free recall of $\mathrm{CVC}$ trigrams was studied yielded results in agreement with those of the original experiment to the effect that the influence of distractor on free recall, if any, is small. Consequently, in comparisons of recognition and free recall the presence of distractors in the former and their absence in the latter does not contribute much to any differences obtained between them.

Studies comparing recognition and recall procedures as measures of retention have been criticized (Bahrick, 1964) on the bases that the comparison groups were not brought to the same level of learning on the two kinds of retention measures and that only "easy" recognition tests were employed in the assessment of retention by means of the recognition procedure. Thus, the general conclusion that curves of retention based on recognition are superior to those based on recall may arise because of these methodological differences. When conditions are employed which surmount Bahrick's criticisms (Bahrick \& Bahrick, 1964; Bruce \& Cofer, 1967), it is found indeed that retention as measured by recognition is not always superior to retention as measured by recall.

However, there is another difference between tests of recognition and recall which can conceivably give an advantage to recall over recognition. This difference lies in the fact that in the typical case recognition of correct items is measured in the presence of distractors; distractors have not ordinarily been employed in the case of recall, and hence the conditions of measurement for recognition and recall are not comparable. Bruce \& Cofer (1967, Exp. 2) reported an experiment in which free recall of trigrams was carried out in the presence of distractors and found that recall scores over six acquisition trials were inferior to recall scores obtained in the absence of distractors. The differences, however, fell short of statistical significance. The present paper reports a replication of this experiment.

\section{SUBJECTS}

Sixty-four student volunteers, satisfying a requirement in introductory psychology at the University of Maryland, were assigned to the four experimental conditions in order of their appearance at the laboratory, subject to the restriction that the sex ratio across groups was kept roughly constant.

\section{MATERIALS AND APPARATUS}

Materials were presented for learning by means of a memory drum at a $2-\mathrm{sec}$ rate. The list to be learned was composed of 28 new CVC trigrams, exactly comparable to those used by Bruce \& Cofer (1967, p. 284), and the distractors used for the Long Recognition (LR) and Short Recognition (SR) conditions for free recall were likewise new CVCs comparable to those used by Bruce and Cofer. The sets of four-digit numbers employed in the number-cancelling task were comparable to those used by Bruce \& Cofer $(1967$, p. 288).

\section{PROCEDURE}

Eight acquisition trials were given each $S$, each trial consisting of the presentation of the $28 \mathrm{CVCs}$ (nine presentation orders being used). In each trial, following presentation of the CVCs, $S$ performed a free recall task under one of the following conditions: (1) Partial free recall (PFR). A recall sheet was provided on which were presented seven of the CVCs from the list, and S was asked to recall as many of the remaining 21 CVCs as he could, in any order in which they occurred to him. Four minutes were given for this recall, but

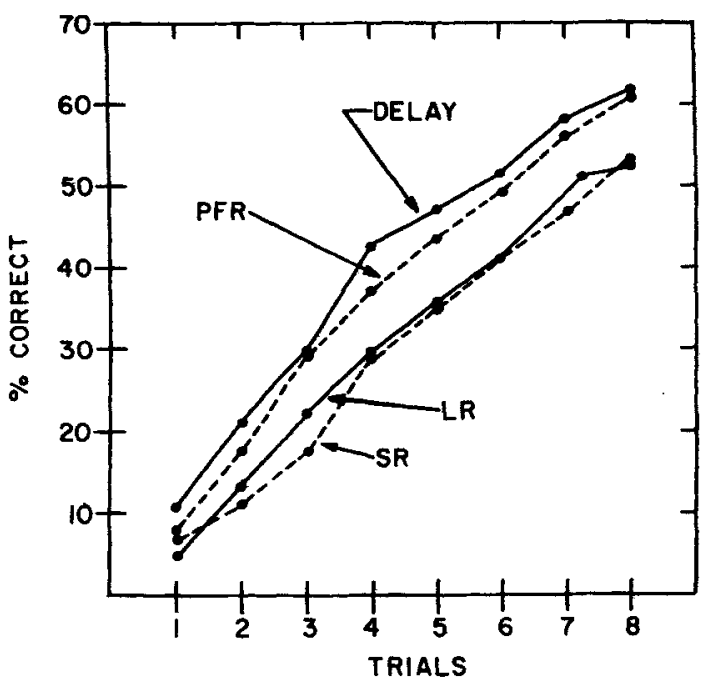

Fig. 1. Mean percentage correct as a function of acquisition trials for the four groups.

recall scores were based on only the first $2.5 \mathrm{~min}$. (2) Delay. After list presentation, $S$ performed a number-cancelling task for $1.5 \mathrm{~min}$. Embedded among the numbers were seven correct CVCs, which $S$ was instructed to encircle as he came to them. Then he attempted to free recall the remaining $21 \mathrm{CVCs}$, having $2.5 \mathrm{~min}$ to do so. (3) Distractors: Short list (SR). Following list presentation, $\mathrm{S}$ had $1.5 \mathrm{~min}$ to find and encircle the seven correct CVCs which were embedded in a set of 35 CVCs (28 distractors). Following this, he attempted to recall the remaining $21 \mathrm{CVCs}$ in $2.5 \mathrm{~min}$. (4) Distractors: Long list (LR). This condition was the same as SR, except that the seven correct CVCs were embedded in a set of $77 \mathrm{CVCs}$ (70 distractors).

\section{RESULTS AND DISCUSSION}

Data for percentage of correct recalls are shown in Fig. 1. The PFR and the Delay groups, which did not have CVC distractors, show better performance than the LR and SR groups which did have distractors. However, the main effect due to conditions was not statistically significant $[F(3,63)=1.84, p>.05$ (the $F$-value required for significance at the .05 level is 2.76$)$ ]. The trials effect is, of course, highly significant $[F(7,392)=269.76, p<.005]$.

Although in neither this experiment nor the one reported by Bruce \& Cofer (1967) were significant results found for the influence of distractors on recall, the consistency of the results suggests that there may be such an effect. The effect, however, under the conditions of these experiments, is clearly a very small one and, if the size of this effect can be generalized to other situations, it is not a major factor in the comparison of retention by means of recognition and recall procedures.

\section{REFERENCES}

BAHRICK, H. P. Retention curves: Facts or artifacts? Psychological Bulletin, 1964, 61, 188-194.

BAHRICK, H. P., \& BAHRICK, P. O. A reexamination of the intertelations among measures of retention. Quarterly Joumal of Experimental Psychology, 1964, 16, 318-324.

BRUCE, D., \& COFER, C. N. An examination of recognition and free recall as measures of acquisition and long-term retention. Journal of Experimental Psychology, 1967, 75, 283-289. NOTE

1. Now at the Laboratory for the Study of Symbolic Processes, Pennsylvania State University, Burrowes Building, University Park, Pennsylvania 16802 